\title{
Artículos
}

\section{Las clases sociales y el modelamiento socioespacial de Temuco, Chile, a finales del siglo XX}

\section{Social classes and socio-spatial modeling of Temuco, Chile, at the end of the 20th century}

Félix Rojo Mendoza*

Rodrigo Hidalgo Dattwyler**

\section{Resumen}

Los cambios en las ciudades están relacionados con la reestructuración del mercado de trabajo y la consiguiente aparición de nuevas clases sociales. Estos grupos, motivados por un gusto espacial, transforman los espacios urbanos. Este trabajo explora las transformaciones espaciales de clases en Teтuco (Chile) entre 1992 y 2002. Obviando los indicadores de segregación residencial, y superando la desterritorialización en los modelos de estratificación social, se observan cambios importantes en la ciudad. Entre ellos, un periurbano de encuentro entre clases muy distintas entre sí, antiguas zonas

* Universidad Católica de Temuco, Departamento de Sociología y Ciencia Política. Dirección: Campus San Francisco, Manuel Montt 56, Temuco, Chile. Correo: frojo@uct.cl ORCID: https://orcid.org/0000-0001-5794-5652

** Pontificia Universidad Católica de Chile. Instituto de Geografía. Dirección: Campus San Joaquín, Av. Vicuña Mackenna 4860, Macul, Santiago, Chile. Correo: rhidalgd@uc.cl ORCID: https://orcid.org/0000-0001-6092-1547

Nota de los autores: Este artículo forma parte del proyecto 412-3852 de la Vicerrectoría de Investigación, Universidad Católica de Temuco, así como del del Fondecyt Regular 1201255, "Los gustos espaciales en la producción de espacios urbanos dentro del Chile neoliberal: el caso de las conurbaciones de Temuco-Padre Las Casas e Iquique-Alto Hospicio". 
obreras que suben en la escala socioespacial, y diversificación espacial de la clase media.

Palabras clave: movimientos espaciales; estratificación socioespacial; gusto espacial; análisis de correspondencias múltiples; ciudad intermedia.

\begin{abstract}
The changes experienced by cities are related to the restructuring of the labor market and the consequent emergence of new social classes. These groups, motivated by spatial preferences, transform urban spaces. This paper explores the spatial transformations of classes in the city of Teтuсо (Chile) between 1992 and 2002. Leaving aside the traditional indicators of residential segregation and overcoming deterritorialization in social stratification models, important changes are observed in the city. Among them, a peri-urban encounter between very different classes, former worker zones that rise in the socio-spatial scale, and the spatial diversification of the ascending middle class.

Keywords: space movements; socio-spatial stratification; spatial preferences; multiple correspondence analysis; intermediate city.
\end{abstract}

\title{
Introducción
}

Para estudiar las transformaciones sociales de los espacios urbanos en las últimas décadas, inevitablemente se debe dar cuenta de los cambios que se registran en el capitalismo global. Puntualmente, aquellos relacionados con la reestructuración en las formas de producción y su consecuente impacto en la aparición de nuevas clases sociales.

Así, y a partir de lo anterior, es posible observar en la actualidad cambios en la estructura de clases, donde destaca la existencia de diferencias entre trabajadores de cuello y corbata y aquellos de la aristocracia laboral, el surgimiento de la clase media o de servicios como la más numerosa e indeterminada (Savage, Dickens y Fielding, 1988), y el retroceso de la clase obrera ${ }^{1}$ (Savage et al., 2013; Ham-

${ }^{1}$ Esto implica que este grupo no necesariamente se trasladó a otro lugar. 
nett y Butler, 2013). Además, y sumado a lo anterior, aparece un tipo de capital cultural alternativo, propio del actual capitalismo global, donde no se consume cultura bajo los parámetros bourdianos, sino más bien se utiliza como una forma de legitimidad dentro del sistema social (Friedman, Savage y Miles, 2015; Hanquinet, Savage y Callier, 2013).

Como consecuencia de este nuevo escenario global, el sistema de producción social del espacio, al estar organizado en torno a la estructura de clases sociales, también experimenta cambios importantes. En este sentido, la producción del espacio urbano sería el resultado de la cristalización del capitalismo citadino actual en los intereses espaciales de clases: grupos diversos que valorizan, disputan y ocupan espacios simbólicamente significativos.

Resulta necesario entonces problematizar en el actuar de las clases sociales en las ciudades. En particular, sustentar la idea de una relación dialéctica entre espacio social y físico, en la cual, por ejemplo, el efecto lugar no actúa independientemente de las relaciones de clases, y estas últimas no tienen sentido fuera de un terreno específico. Las relaciones que se forjan con el espacio, por tanto, forman parte del sistema que establece cómo determinados grupos definen su posición social (Ripoll y Tissot, 2010).

Bajo esta constatación, el presente trabajo tiene por objetivo identificar las diversas clases sociales presentes en la ciudad de Temuco, ${ }^{2}$ región de la Araucanía, en Chile, y determinar los cambios espaciales que éstas experimentaron entre los años 1992 y 2002, década que concentra una parte importante de las transformaciones del mercado del trabajo en esa nación (León y Martínez, 2001; De Mattos, 2002). Se asumirá que dichos cambios fueron producto de gustos espaciales de clases sociales determinadas, especialmente aquellos grupos medios que tienen las posibilidades de concretar sus deseos en determinadas zonas de la ciudad.

Alejado de los indicadores convencionales de segregación residencial, y llevando los modelos tradicionales de estratificación social al espacio, este estudio pretende, además, aportar a la discusión so-

${ }^{2}$ Una de las diez comunas con mayor crecimiento poblacional en Chile, según el censo de 2017. 
bre cómo observar las transformaciones socioespaciales en las ciudades de hoy.

\section{Las dinámicas de clases sociales en el reordenamiento urbano}

Las clases son entidades sociales ordenadas bajo un mecanismo jerárquico y desigual que da existencia a la estratificación de una determinada sociedad.

Para entender la clase social desde un punto de vista analítico, es necesario relevar las variables presentes en distintas perspectivas teóricas. Entre las más importantes: la marxista, centrada en las relaciones de producción y el control en el proceso productivo; la weberiana, relacionada con las destrezas ocupacionales como educación-calificación; y la bourderiana, vinculada al habitus de clase, es decir, al sistema de representaciones que las personas utilizan inconscientemente en distintas situaciones (Bourdieu, 1997). Bajo esta última perspectiva, los grupos sociales se distinguen entre sí por los patrones de gusto y distinción que determinan los capitales económicos y culturales que poseen (Bourdieu, 2006).

Por tanto, y considerando la aproximación que Bourdieu tiene a la clase social, los agentes se distribuyen en el espacio social de acuerdo al volumen de capital que posean y a la estructura de sus capitales; es decir, el peso relativo de los distintos capitales en el volumen total de sus activos (Bourdieu, 1989).

Estas tres formas de entender las clases sociales no funcionan de manera independiente, por lo que se generan correspondencias entre el control, la calificación y el habitus. Además, dependiendo de la categoría ocupacional en la que se desempeñe una persona, variable que generalmente integra a las perspectivas marxistas y weberianas, se tendrá un conjunto de disposiciones de clases o habitus.

Cada una de estas corrientes teóricas presenta distintas implicancias urbanas en cuanto a las formas de ordenamiento socioespacial. Desde el marxismo, la estructura espacial en las ciudades tiene su origen en la forma que actualmente opera el capitalismo. Ello implica que la producción del espacio (en sus dos sentidos lefebvrianos, como medio de uso-consumo y como lugar de producción) está 
sustentada sobre la base de las soluciones espaciales, las cuales corresponden a las intensificaciones del capital financiero sobre el espacio a partir de la llamada cuestión inmobiliaria (Lefebvre, 2013; Brenner, 2013; Harvey, 2014), hecho que ya fue constatado por Engels (2006 [1872]) en la segunda parte del siglo XIX. De esta forma, cualquier patrón de consumo de viviendas implicaría siempre una correspondencia entre el capital económico que tenga una persona y el deseo de ocupar determinado lugar en la ciudad (Smith, 2012).

Por otro lado, si bien Max Weber no proyectó su reflexión de los sistemas de estratificación sobre el espacio urbano, sí es posible constatar que el resultado de dicho ordenamiento social estaría reflejado en las ciudades. En este sentido, y a diferencia del enfoque marxista, Weber (2014) reconoce que la estratificación social es la desigual repartición del poder en tres ámbitos: económico, social y político, donde la noción de clase social sólo se relaciona con lo económico y las formas de inclusión al mercado laboral. De esta manera, las personas ocupan un determinado lugar en una sociedad, dependiendo de los bienes y servicios, lo cual se reflejaría en las formas que adquiere la ciudad en términos sociales.

Similar argumentación utiliza Bourdieu (2018), quien reconoce que el espacio social se objetiva en el espacio físico, contemplando con ello todas las diferencias que se dan en el primer espacio. En este sentido, los agentes que forman parte de un determinado espacio físico presentarán condiciones diferenciadas de apropiación de los bienes y servicios que tienen estas áreas dependiendo de los capitales que posean, $y$, por tanto, de la distancia física que la posesión de dichos capitales determinará. La distribución de determinados bienes y servicios en el espacio físico, por consiguiente, sería el resultado de los diferentes espacios sociales físicamente objetivados, los cuales, además, tienden a entremezclarse entre sí, dando como resultado determinadas concentraciones en el interior de la ciudad (Bourdieu, 2018).

Así, y más allá de representar las diferencias y jerarquías de grupos sociales en una sociedad, la clase es una entidad que contiene los aspectos centrales para descifrar la relación entre estructura e individuo en la producción del espacio urbano, ya que no sólo opera como una dimensión material para designar a distintos grupos socia- 
les, sino también es el resultado de procesos de reproducción simbólica vinculados al habitus de clase, donde el espacio urbano juega un papel preponderante en la resignificación de gustos y distinciones en diversos grupos. E incluso, mientras más complejo se vuelve el sistema de clases en una sociedad determinada, observado a través de las distinciones presentes en el mercado ocupacional, el conjunto de disposiciones de cada grupo no siempre corresponderá a la magnitud del capital económico que posean, existiendo así un diferencial entre la expectativa del espacio por habitar y las posibilidades materiales para poder concretarlo.

Bajo este argumento, la relación entre espacio social y espacio físico se concibe como algo dinámico, en constante cambio, determinado por las posibilidades concretas que tienen las distintas clases de moverse en la dirección que sus sistemas de disposiciones les indiquen. La ciudad en términos materiales, por tanto, si bien es el resultado de la acción concreta del capital financiero, expresado en la industria inmobiliaria y la desregulación estatal, no puede analizarse desechando la influencia que determinados gustos espaciales de clases tienen en su ordenamiento socioespacial.

A partir de lo anterior, por ejemplo, se constata que en espacios metropolitanos de América Latina, como Santiago de Chile (Link, Valenzuela y Fuentes, 2015; De Mattos, 2002), Río de Janeiro (Preteceille y Ribeiro, 1999), Buenos Aires (Ciccolella, 1999), Ciudad de México (Horbath, 2002) y Bogotá (Fuentes y Link, 2014), existen desplazamientos de ciertos grupos sociales hacia la periferia, generando en muchos casos una ciudad dual, en donde además la relación de las clases medias con los sectores altos repercute en la privatización de los espacios públicos.

Del total de clases que existen en las sociedades actuales, son más bien las clases medias y altas aquellas que pueden ver el conjunto de sus aspiraciones espaciales realizadas, quedando mayormente excluidos los grupos obreros o precarios, los cuales no tienen el capital económico suficiente, a pesar de que su preferencia espacial pueda estar asociada a gustos correspondientes a otras clases sociales (Hamnett y Butler, 2013). Sin embargo, y a pesar de carecer de capital económico, de igual forma estos últimos grupos intentan apropiarse de los espacios a través de otros mecanismos relacionados con 
movimientos sociales provivienda, los cuales apelan al derecho a la ciudad.

Existen dos motivos por los cuales particularmente la clase media, a diferencia de cualquier otro grupo social en el capitalismo actual, es más importante en términos del impacto en los espacios urbanos. Por un lado, este grupo siempre está intentando reemplazar la falta de capital material a través del consumo de bienes variados, entre los cuales se cuenta la vivienda. En este sentido, la aparición de un tipo específico de individualidad y filosofía estética asociado a este grupo conlleva determinados patrones de consumo en las ciudades (Ley, 1980; Bridge, 2001). Por otro lado, es un grupo abierto a distintas influencias, siendo menos estructurado que las clases altas, a las cuales tiende a seguirse en una espiral de auge y descenso de modas sociales (Simmel, 1986).

En Chile se reconocen varias clases medias, muchas de las cuales se diferencian históricamente respecto a las trayectorias laborales de sus padres. Esto produce que existan una serie de diferencias internas en este grupo respecto al consumo material y simbólico, lo cual lleva a identidades muchas veces ambivalentes, sentimientos de inconsistencia entre múltiples posiciones, y una amplitud de estilos de vida y prácticas culturales. Debido a esta diversidad, no se puede hablar de Chile como una sociedad mesocrática (Méndez, 2008; Mac-Clure, 2012; Gayo, Méndez y Teitelboim, 2016), y menos de un espacio urbano homogéneo en estos términos.

\section{Modelos de clases sociales en la ciudad: los desafíos investigativos}

Como se dijo anteriormente, las clases sociales representan dispositivos de actuación a partir de los cuales las personas funcionan en las sociedades. Sin embargo, y más allá de la importancia que esta categoría parece tener para la comprensión de las transformaciones urbanas, muchos de los estudios referidos a la ciudad no consideran la profundidad analítica que implica trabajar con este concepto.

En este sentido, los modelos de clases deben repensarse no sólo para capturar adecuadamente los cambios en los patrones de produc- 
ción global, sino también con el objetivo de visualizar las consecuencias de estas transformaciones en el espacio urbano. Para que ello ocurra, se deben superar dos problemas teórico-metodológicos: el establecimiento de modelos de clases sin la consideración espacial, y la mirada espacial de clase sin la necesaria profundidad conceptual.

\subsection{Primer problema teórico-metodológico: clases sin espacios}

La dimensión central para la conformación de grupos en los estudios de estratificación social comúnmente es la rama o grupo ocupacional de pertenencia, constituyendo con ello una estrecha relación entre estratificación social y ocupacional. Así, la variable ocupación es utilizada fuertemente en la mayor parte de los modelos de estratificación, relevando con ello al trabajo como fundamento de la vida social en general y, por tanto, las oportunidades que tienen las personas de ascender en la estructura social a partir de sus determinantes en el mercado laboral.

Un ejemplo de lo anterior está representado en la CIUO (Clasificación Internacional Uniforme de Ocupaciones), la cual integra las perspectivas neomarxistas y neoweberianas, e indirectamente a las bourdianas. Dicha clasificación define grupos sociales de acuerdo a dos dimensiones combinadas en escalas secuenciales: por un lado, la ocupación específica de una persona; y por otro, las habilidades ocupacionales relacionadas con la educación en el desempeño de una labor (Barozet et al., 2009).

Un modelo que utiliza la ocupación como aspecto central para el estudio de la estratificación social corresponde a la propuesta de Erikson y Goldthorpe (1992), una de las más difundidas a nivel mundial en este tipo de trabajos. La particularidad de esta propuesta es que fue elaborada para sociedades industriales combinando tres dimensiones: control y propiedad de medios de producción, prestación de servicios de alta o baja autonomía, y manualidad en la labor realizada (Erikson y Goldthorpe, 1992).

A pesar de las críticas al trabajo de Erikson y Goldthorpe, entre las cuales destacan la poca consideración de variables como el género, la raza o la etnia en la discusión, o la tendencia a la descripción 
homogénea de la clase media asalariada (Savage et al., 2013), este modelo alcanzó gran influencia a nivel internacional. Y Chile no ha sido la excepción, lo cual queda demostrado a través de diversos trabajos aplicados (Torche y Wormald, 2004; Espinoza, Barozet y Méndez, 2013; Mc-Clure et al., 2014). De todos ellos, el caso más conocido de adaptación al contexto chileno corresponde al trabajo de Torche y Wormald (2004), quienes crearon ocho categorías basadas en la combinación de tres dimensiones relacionadas con el modelo original.

A las aplicaciones del modelo del Erikson y Goldthorpe en Chile, se suma otro conjunto de trabajos, muchos de los cuales han centrado su análisis en los cambios de la estructura ocupacional de las últimas cuatro décadas (Raczynski, 1973; Martínez y Tironi, 1985; León y Martínez, 2001; Portes y Hoffman, 2003). En ellos se destacan: la disminución de estratos sociales relacionados con actividades agrícolas y obreras, la terciarización de la fuerza de trabajo, la burocratización del trabajo asalariado en el mundo privado, y la pérdida del empleo estatal.

Si bien los modelos de estratificación social se han adaptado a las nuevas configuraciones de clase en el capitalismo actual; no ocurre lo mismo cuando se traslada esta discusión a las transformaciones socioespaciales que experimentan las ciudades. De esta manera, los modelos de estratificación social analizan las clases y su movilidad en términos ocupacionales, sin una referencia concreta a un espacio determinado, generando con ello una visión no relacional entre espacio y clase. ¿Qué pasa con la geografía social en las ciudades?, o ¿cómo se movilizan y establecen las nuevas clases sociales en el nuevo espacio del capital?, conforman preguntas relevantes en el momento de estudiar los cambios sociales en las ciudades.

\subsection{Segundo problema teórico-metodológico: espacios sin clase}

Por otro lado, la categoría de clase es tratada muchas veces como una entidad metodológica, vacía de todo contenido explicativo que permita establecer distinciones reales de grupos sociales en los espacios urbanos. Así ocurre con la noción de segregación residencial, la cual 
tiende a tomar nominalmente el concepto de clase social para describir las transformaciones en los espacios urbanos, sin una adecuada profundización.

En los estudios de segregación residencial, los desequilibrios en la localización de grupos sociales en los espacios urbanos tienden a ser medidos considerando las diferencias que se registran en variables proxy a la clase, como bienes materiales, ingresos o educación. Con este objetivo se aplican modelos como los de disimilitud y algunos de sus derivados, como el índice de aislamiento social o el índice de exposición (Rodríguez, 2001).

Sin embargo, la utilización de variables proxy a la clase social no asegura que la segregación exista entre clases sociales diferentes, ya que el aumento de los indicadores de educación y acceso al crédito en la población general, incluso de los sectores más pobres, hace que estas variables no sean pertinentes para hablar de segmentación social en los espacios urbanos. Si a esto se suma que las consideraciones de clase se hacen sobre la base de grupos sociales definidos bajo mecanismos altamente variables, y que existe escasa reflexión respecto a la escala de aplicación (Ruíz-Tagle y López Morales, 2014), la segregación residencial es inapropiada como indicador para analizar los espacios urbanos.

Un aporte interesante que busca superar las tradicionales mediciones en segregación residencial está representado en el trabajo de Link, Valenzuela y Fuentes (2015), quienes, a partir de un análisis factorial de correspondencias simples, y considerando variables ocupacionales, identifican áreas sociales en el espacio metropolitano de Santiago. El resultado es la elaboración de tipologías socioespaciales sobre esta área (las cuales expresan la superación de los indicadores tradicionales a partir del uso de variables ocupacionales por sobre las de ingreso), la posibilidad de evaluar la estructura socioterritorial latente en el Gran Santiago (a partir del análisis factorial) y una mejor representación espacial de la distribución social (Link, Valenzuela y Fuentes, 2015).

En una dirección similar aparece el trabajo de Fuentes et al. (2017) que, con base en el modelo de Erikson y Goldthorpe de 1992, relacionan la oferta/ demanda de trabajo y los lugares de residencia. Aplicando tanto los valores aproximados de los bienes raíces como 
los modelos de clase antes mencionados, los resultados de este estudio indican que las posibilidades de movilidad ascendente en el Gran Santiago se vinculan con la forma en cómo opera el mercado inmobiliario y los atractivos laborales de estas zonas, contribuyendo de esta manera a entender la desigualdad socioterritorial en dicho espacio urbano (Fuentes et al., 2017).

A pesar de estos esfuerzos por relacionar las clases sociales con los espacios urbanos, lo cierto es que un número importante de trabajos aún opera con los indicadores tradicionales de segregación residencial, siendo por ello necesario introducir una visión crítica desde un punto de vista teórico-metodológico.

\section{Metodología}

Este trabajo tiene una finalidad descriptiva y exploratoria, utilizando para ello el procesamiento estadístico de datos censales de 1992 y 2002. A partir de estas bases se reconocieron dos niveles de información relevantes: a) la pregunta respecto a la ocupación de la población activa, $\mathrm{y} b$ ) a nivel espacial, las zonas censales y entidades rurales de Temuco (véase el Mapa 1).

Para trabajar con la variable ocupación, proxy a la clase social, fue necesario realizar distintos procedimientos de recodificación, compatibilizando de esta forma el número de categorías con las cuales se captura esta dimensión en los censos de 1992 y 2002. Para ello, se consideraron los mecanismos que establece la CIUO-88 (Clasificación International Uniforme de Ocupaciones), a partir de la cual se redujeron los distintos niveles de especificidad ocupacional a nueve categorías ordenadas jerárquicamente en términos de su prestigio social $^{3}$ (véase el Cuadro 1).

Cabe destacar, tal como se mencionó anteriormente, la existencia de modelos que intentan dar cuenta de la estructura de clases sociales en una determinada sociedad, integrando para ello las cate-

${ }^{3}$ No se consideró la categoría Fuerzas Armadas, ya que ésta opera bajo otras dimensiones que determinan la entrega del control y poder en el interior del grupo, propia de la institución en la que están inmersos este tipo de ocupados. 
gorías ocupacionales bajo variados tipos de ordenamientos previos, dependiendo si se quiere relevar la propiedad y control, la autonomía, calificación, manualidad o el conjunto de ellas en las personas que forman parte de un determinado mercado del trabajo. Así, modelos de clases sociales ampliamente difundidos a nivel internacional como los de Erikson y Goldthorpe (1992), adaptados de distintas formas al contexto chileno (Torche y Wormald, 2004; Espinoza, Barozet y Méndez, 2013; Mac-Clure, Barozet y Maturana, 2014), o más recientemente el de Savage et al. (2013), parten de la formación de categorías ocupacionales consolidadas, tal como lo hizo el presente trabajo.

Por tanto, y considerando estas categorías, se calcularon los pesos porcentuales y los puntajes estandarizados de las ocupaciones por cada una de las zonas censales de Temuco. Con estos antecedentes, y aplicando una combinación de análisis de correspondencias múltiples $(\mathrm{ACM})$ y análisis de conglomerados jerárquicos (Lebart, Morineau y Piron, 1995; Link, Valenzuela y Fuentes, 2015), se obtuvieron finalmente los clústeres o clases socioespaciales para el periodo intercensal analizado.

Una vez obtenidos los resultados, éstos fueron reordenados bajo nuevas categorías. Así, profesionales, técnicos y oficinistas pasaron a denominarse grupos medios, mientras operarios-artesanos y operadores formaron parte de los grupos obreros. Esta categorización del análisis ${ }^{4}$ tuvo como objetivo dar un mejor contexto a los resultados, considerando que estas nuevas tipologías sociales de clases presentan coherencia interna en términos de calificación, manualidad y control en el mercado laboral (véase el Cuadro 1). Además, constituyen dos grupos que históricamente han estado en posiciones encontradas dentro de la jerarquía de las sociedades modernas, lo cual puede influenciar la construcción de determinados gustos espaciales de clase.

El procesamiento de la información se llevó a cabo mediante el software SPSS 20 para la información contenida en los censos, y ArcGis 10.5 para la georreferenciación de las clases socioespaciales presentes en Temuco.

${ }^{4}$ Que siguió los lineamientos del trabajo de Preteceille y Ribeiro (1999), replicado en Chile por De Mattos (2002). 


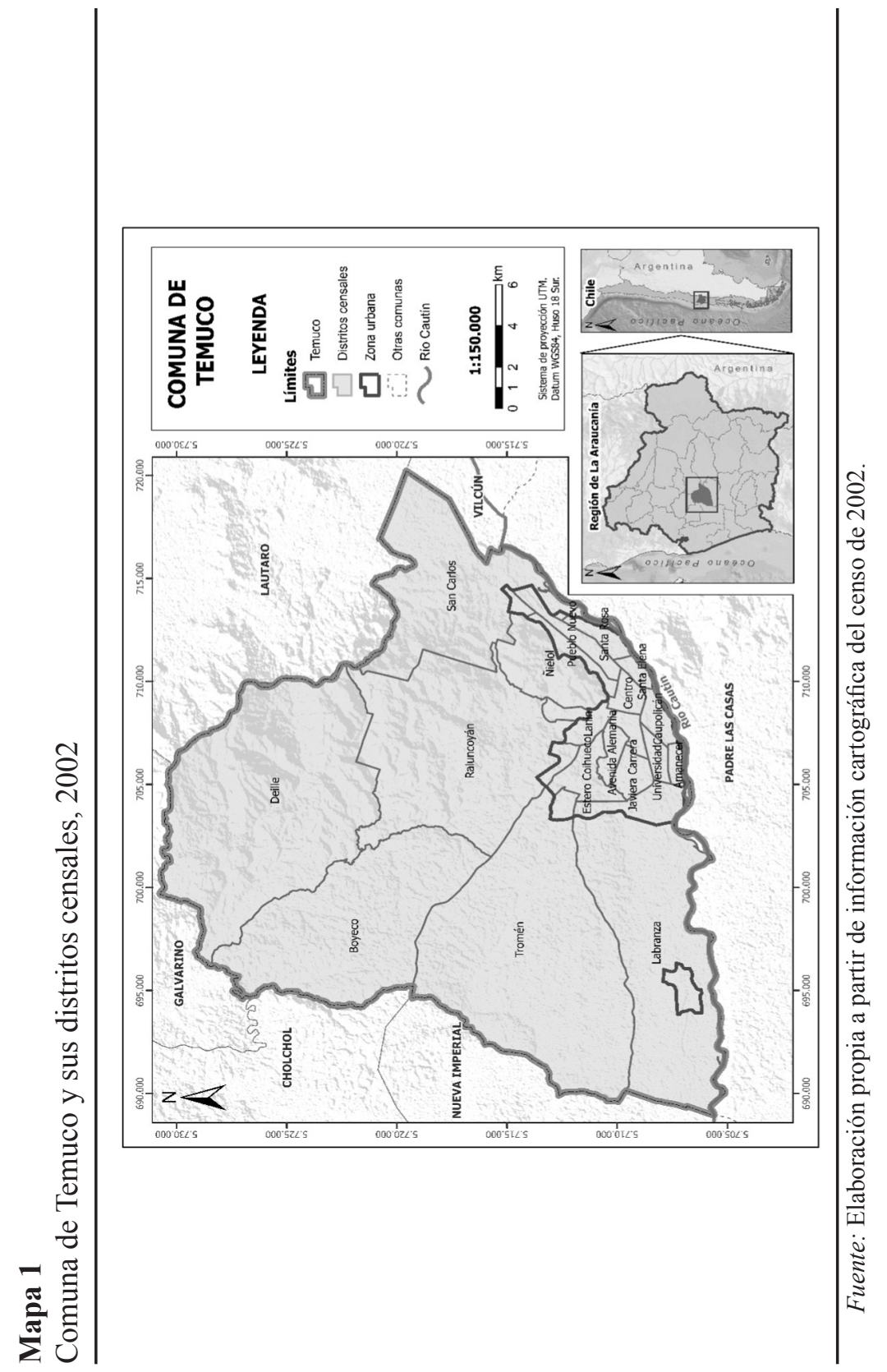




\section{Cuadro 1}

Categorías ocupacionales contempladas en el análisis

\begin{tabular}{|c|c|c|}
\hline Grupos ocupaciones CIUO-88 & Abreviatura & $\begin{array}{l}\text { Macrogrupos } \\
\text { de referencia }\end{array}$ \\
\hline $\begin{array}{l}\text { Miembros del poder ejecutivo- } \\
\text { legislativo, directivos públ./priv. }\end{array}$ & Dirigentes & Dirigentes \\
\hline Profesionales, científicos e intelectuales & Profesionales & \multirow{3}{*}{ Grupos medios } \\
\hline Técnicos y profesionales nivel medio & Técnicos & \\
\hline Empleados de oficina & Oficinistas & \\
\hline $\begin{array}{l}\text { Trabajadores de servicios, vendedores } \\
\text { de comercio y mercados }\end{array}$ & Servicios & Servicios \\
\hline $\begin{array}{l}\text { Agricultores y trabajadores calificados } \\
\text { agropecuarios/ pesqueros }\end{array}$ & Agrícolas & Agrícolas \\
\hline $\begin{array}{l}\text { Oficiales, operarios, artesanos de artes } \\
\text { mecánicas y otros oficios }\end{array}$ & $\begin{array}{l}\text { Operarios } \\
\text { y artesanos }\end{array}$ & \multirow{2}{*}{ Grupos obreros } \\
\hline $\begin{array}{l}\text { Operadores de instalaciones y máquinas } \\
\text { y montadores }\end{array}$ & Operadores & \\
\hline Trabajadores no calificados & No calificados & No calificados \\
\hline
\end{tabular}

Fuente: Elaboración propia a partir del CIUO-88.

El software ArcGis 10.5 permitió, además, determinar las transformaciones de estas clases sociales entre 1992 y 2002. Para ello se establecieron tres campos de movimientos: $a$ ) dicotomía de cambio (se mantuvo o cambió de clúster); b) dirección del cambio (sube o baja de clúster, o se mantiene); y c) magnitud del cambio. En este último punto se establecieron nueve niveles de cambio, desde el valor +4 a -4 , donde 0 corresponde al neutro de manutención del clúster, $y$ el +4 y -4 corresponden a los máximos grados de transformaciones en distintas direcciones.

\section{Las transformaciones del perfil socioespacial de Temuco, 1992-2002}

Actualmente, Temuco presenta una importante característica a nivel nacional: es una de las diez comunas con mayor crecimiento en Chile según el censo de 2017 (INE, 2018). Sólo durante los últimos 36 años de la ciudad, los habitantes de Temuco aumentaron a $32.7 \%$ 
más de los que existían en 1982, mientras que las viviendas se incrementaron en $61.2 \%$ en el mismo periodo. La magnitud de esta expansión se traduce en que esta comuna se ha constituido en un importante espacio de atracción de población e inversiones de variada índole.

A pesar del crecimiento y la relevancia que ha adquirido la ciudad en las últimas décadas, los estudios urbanos sobre este espacio son escasos, y los que existen se concentran en mostrar la presencia desigual de grupos sociales en el espacio (Garín, Salvo y Bravo, 2009), las disputas por el derecho a la ciudad y la vivienda a mediados del siglo pasado (Vergara, Gola y Huiliñir, 2015), o los procesos de crecimiento urbano del último tiempo (Marchant, Frick y Vergara, 2016). Por consiguiente, aún falta explorar las transformaciones socioespaciales producto de la emergencia de nuevos actores sociales en la ciudad.

Observando los porcentajes de ocupaciones en Temuco para los años 1992 y 2002, se constata que las clases medias, formadas por profesionales, técnicos y oficinistas, conforman uno de los grupos que más crecimiento experimentan en este periodo censal (véase el Cuadro 2). Y si bien este incremento está muy por debajo del registrado por la clase agrícola, su magnitud tiende a ser más considerable dentro de Temuco, en especial en el interior de las zonas urbanas, razón por la cual su impacto en las transformaciones de la ciudad resulta más interesante de indagar. ${ }^{5}$

Con el fin de conocer las clases sociales y sus cambios en Temuco en el periodo 1992-2002, los porcentajes de cada categoría ocupacional fueron transformados en puntajes estandarizados y recodificados en los términos señalados en la metodología. ${ }^{6}$ A partir de este procesamiento, se aplicó un análisis de correspondencias múltiples (ACM), del cual resultaron los modelos para ambos años.

Para 1992 el ACM genera dos factores latentes que explican el $89.6 \%$ de la variabilidad de las categorías ocupacionales que residen

${ }^{5}$ El crecimiento de la clase agrícola durante este periodo se traduce en una ocupación espacial principalmente rural, alejada de los límites urbanos de la ciudad.

${ }^{6}$ Todo esto por cada una de las zonas censales y entidades rurales de los censos de 1992 y 2002, tal como se especificó en la metodología. 
en distintas zonas censales de Temuco, estableciendo con ello una fuerte relación entre espacio habitado y actividad ocupacional de las personas.

\section{Cuadro 2}

Porcentajes de ocupaciones presentes en Temuco, 1992-2002

\begin{tabular}{lccc}
\hline Ocupaciones & $\mathbf{1 9 9 2}$ & $\mathbf{2 0 0 2}$ & $\begin{array}{c}\text { Diferencia } \\
\mathbf{1 9 9 2 - 2 0 0 2}\end{array}$ \\
\hline Dirigentes & 5.4 & 5.5 & 0.1 \\
Profesionales & 10.4 & 10 & -0.4 \\
Técnicos & 6.2 & 8.8 & 2.6 \\
Oficinistas & 10.9 & 4.3 & -6.6 \\
Servicios & 19.7 & 10.3 & -9.4 \\
Agrícolas & 4.7 & 18.6 & 13.9 \\
Operarios y artesanos & 17.1 & 11.4 & -5.7 \\
Operadores & 6.9 & 4.4 & -2.5 \\
No calificados & 18.7 & 26.7 & 8 \\
Total & 100 & 100 & \\
\hline
\end{tabular}

Fuente: Elaboración propia a partir de los censos de 1992 y 2002.

En un primer factor, que denominaremos "composición espacial interna de la clase media", las categorías ocupacionales que más aportan a dicho componente son los técnicos y oficinistas. Lo anterior evidencia que, si observamos un espacio habitado por la clase media de aquel entonces, éstas estarán conformadas principalmente por esas dos ocupaciones, dejando fuera a los profesionales que comúnmente suelen entrar en esta categoría meso de la jerarquía social (véase el Cuadro 3).

Por otro lado, las categorías ocupacionales que más contribuyen a entender el segundo factor del modelo, que llamaremos "relaciones espaciales interclase", corresponden a los oficinistas y operarios-artesanos. Este componente se relaciona con la posibilidad de cohabitación de distintas clases en un mismo espacio. Así, para el año 1992 es posible observar que la relación espacial de clases más importante se da entre grupos medios, conformados por los oficinistas, y grupos obreros integrados por operarios/ artesanos. Ambos 
grupos representan clases ubicadas en una posición jerárquica distinta en la estructura social de ese entonces en la ciudad de Temuco (véase el Cuadro 3).

Sin embargo, y a pesar de esto último, la determinación espacial de clase sigue siendo relevante en la ciudad al inicio de la década del noventa, configurando con ello un espacio urbano con claras diferencias entre grupos altos, medios y bajos, marcando elevados niveles de segmentación sociorresidencial. Este importante grado de relación clase-espacio y, por tanto, de cierta rigidez en la estructura socioespacial de la época en la ciudad, se sustenta en que el porcentaje de explicación que aporta el segundo factor del modelo (37.9\%) es más bajo que el primero (51.6\%).

Por otro lado, los dos factores que resultan del ACM para 2002 explican el $73.3 \%$ de la variabilidad de ocupaciones que habitan la ciudad, 16.2\% menos respecto a lo que ocurría en 1992. En este sentido, en el periodo intercensal analizado la clase no parece explicar con tanta claridad el lugar de residencia dentro de la ciudad como sí lo hacía en 1992, estableciendo con ello una mayor mixtura social del espacio urbano hacia el nuevo milenio, en especial, y como se detallará más adelante, en aquellas zonas que históricamente fueron el refugio de las clases obreras y menos calificadas.

De esta manera, y al igual que en 1992, son las categorías de técnicos y oficinistas las que presentan una mayor correlación con el factor 1, reiterando con ello la vinculación en el habitar que existe entre estas dos categorías pertenecientes al grupo medio. Este factor, sin embargo, aporta $46.7 \%$ al grado de explicación de las relaciones internas de la clase media en un mismo espacio, casi 5\% menos de lo que contribuía diez años antes. Lo anterior implica entonces que la posibilidad de encuentro en un mismo espacio entre estas dos categorías ocupacionales de grupos medios se debilita en el tiempo, introduciendo probablemente nuevos actores que diversifican el escenario de la clase media dentro de Temuco.

Este fenómeno, de mayor heterogeneidad de los sectores medios en Chile, se vincula principalmente a las formas de consumo introducidas por los principios neoliberales en la década del ochenta (Méndez, 2008; Gayo, Méndez y Teitelboim, 2016). Dichos patrones hacen que exista más de una clase media y, por tanto, una multipli- 
cidad de zonas socioespaciales vinculadas a este grupo en las ciudades, proceso del cual Temuco no está ajeno en el periodo analizado.

\section{Cuadro 3}

Contribuciones de las categorías ocupacionales

a los factores del ACM, 1992-2002

\begin{tabular}{lccccc}
\hline & \multicolumn{2}{c}{1992} & & \multicolumn{2}{c}{2002} \\
\cline { 2 - 3 } \cline { 5 - 6 } \cline { 5 - 6 } Dirigentes & Factor 1 & Factor 2 & & Factor 1 & Factor 2 \\
Profesionales & .252 & .356 & & .446 & .221 \\
Técnicos & .495 & .291 & & .364 & .510 \\
Oficinistas & .776 & .426 & & .698 & .475 \\
Servicios & .819 & .543 & & .821 & .048 \\
Agrícolas & .626 & .234 & & .598 & .042 \\
Operarios y artesanos & .570 & .083 & & .442 & .011 \\
Operadores & .264 & .673 & & .050 & .572 \\
No calificados & .540 & .443 & & .408 & .280 \\
\cline { 1 - 2 } & .309 & .371 & & .383 & .231 \\
\hline
\end{tabular}

Fuente: Elaboración propia a partir de los censos de 1992 y 2002.

De igual forma, y en cuanto al factor 2, se reitera el mismo sentido interpretativo que se entregó a este componente en el año 1992, con dos diferencias importantes. La primera, el porcentaje de explicación de este factor baja a $26.5 \%$, por lo cual el grado de relación interclase en un mismo espacio decrece en el periodo analizado. Sin embargo, y como segunda diferencia importante, si antes la convivencia de dos clases distintas en el espacio se daba entre grupos operarios-artesanos y oficinistas, para 2002 esta relación se da entre la primera categoría ocupacional y los grupos profesionales. Es decir, bajo estos antecedentes, las relaciones sociales entre diversas clases en un mismo espacio son menos frecuentes respecto a 1992, pero más intensas entre las categorías ocupacionales ubicadas a mayor distancia en la jerarquía social (véase el Cuadro 3)

Esta mayor mixturación social en determinados espacios es posible en este periodo debido a la llegada de profesionales y técnicos a zonas que históricamente habían acogido sólo a clases obreras. Esto hace que independiente de la disminución en el grado de relacio- 
nes de clases a nivel espacial, constatada a partir del segundo factor del modelo correspondiente al año 2002, éstas se intensifican con el tiempo en términos que dichas vinculaciones se dan entre grupos sociales cada vez más alejados el uno del otro.

\section{Clases, espacios y relaciones sociales en Temuco, 1992-2002}

Considerando las puntuaciones entregadas por ACM para los dos años analizados, el siguiente paso fue aplicar un análisis de clasificación de conglomerados jerárquicos (ACCJ) a partir de las puntuaciones obtenidas para cada zona censal de Temuco. Así, y observando el historial de conglomeración, se decidió conformar siete clústeres o tipologías socioespaciales para esta ciudad en 1992 y $2002,{ }^{7}$ los cuales representan a las clases sociales existentes en aquella época. Dichas clases, además, fueron ordenadas posteriormente siguiendo la jerarquía que impone el sistema de estratificación social. Para ello se calcularon las distancias entre las ocupaciones ubicadas en la parte más alta de este sistema, dirigentes y grupos medios, y aquellas que están en la parte más baja, obreros y trabajadores no calificados ${ }^{8}$ (véase el Cuadro 4).

A partir de lo anterior, el clúster espacial 2, que concentraba a las clases sociales más altas en 1992, presentaba una diferencia interna con las clases más bajas, obrera y no calificada, de 33.5\%. En la medida que se desciende en la escala socioespacial, las diferencias se reducen, llegando a invertirse porcentualmente la presencia de determinadas ocupaciones. Por otro lado, el clúster 1 agrupaba a las clases medias bajas en espacios que en $95 \%$ eran rurales, dentro de los cuales habitaban principalmente trabajadores agrícolas y no calificados (véase el Cuadro 4).

${ }^{7}$ El criterio utilizado para establecer el número de clústeres fue el mismo para los dos censos analizados, contemplando los cinco puntos de desviación estándar como la frontera para distinguir dichos grupos.

${ }^{8}$ No se consideraron las categorías ocupacionales de servicios y agrícolas, ya que éstas no representan los extremos de la jerarquía socioocupacional. 


\section{Cuadro 4}

Clases sociales según diferencias porcentuales internas entre ocupaciones de los clústeres de Temuco para 1992

\begin{tabular}{lcl}
\hline Clúster espacial & $\begin{array}{c}\text { (dir+medios) }- \\
\text { (obreros }+ \text { no calif.) }\end{array}$ & Clases sociales \\
\hline Clúster 2 & $33.5 \%$ & Muy alta \\
Clúster 6 & $26.6 \%$ & Alta \\
Clúster 4 & $25.9 \%$ & Media alta \\
Clúster 5 & $-5.1 \%$ & Media \\
Clúster 1 & $-17.1 \%$ & Media baja \\
Clúster 7 & $-39.6 \%$ & Baja \\
Clúster 3 & $-49.2 \%$ & Muy baja \\
\hline
\end{tabular}

Fuente: Elaboración propia a partir del censo de 1992.

Ordenando estos clústeres espaciales bajo los mismos principios jerárquicos utilizados en el análisis de 1992, es posible observar que para el año 2002 existen cambios internos en la conformación de las distintas clases sociales. Así, mientras en los clústeres que presentan una mayor concentración de grupos dirigentes y medios -es decir, las clases medias y altas de la ciudad- las diferencias internas con otros grupos ocupacionales aumentan respecto al año 1992, en zonas de clases más bajas - donde es común que habiten obreros y no calificados- las distancias con otras categorías ocupacionales tienden a disminuir en el periodo analizado (véase el Cuadro 5).

Otro cambio importante se relaciona con la estructura social de los espacios rurales de Temuco. Así, si bien sigue existiendo en 2002 una tipología espacial que concentra gran parte de las zonas rurales de la comuna, representado en este caso por el clúster 4 , la estructura ocupacional interna varía, aumentando la presencia de trabajadores no calificados de 16.3 a $33.6 \%$, y bajando los trabajadores agrícolas de 62.7 a $35 \%$ en el periodo analizado (véase el Cuadro 6).

Lo anterior indica un proceso de transformación en las formas de habitar del grupo con menos calificación de la población activa, la cual pasa de ser eminentemente urbana a convivir en espacios rurales. Por otro lado, la baja en la presencia de trabajadores agrícolas en las zonas rurales de Temuco obedece a dos procesos concatenados: 
el desplome de la actividad agrícola en el periurbano de la ciudad, y el cambio forzado de ocupación, que desemboca en el desempeño de actividades que no necesitan una calificación específica. ${ }^{9}$

\section{Cuadro 5}

Clases sociales según diferencias porcentuales internas entre ocupaciones de los clústeres de Temuco para 2002

\begin{tabular}{lcl}
\hline Clúster socioespacial & $\begin{array}{c}\text { (dir+medios) } \\
\text { (obreros }+ \text { no calif. }\end{array}$ & Categorías sociales \\
\hline Clúster 2 & $85.8 \%$ & Muy alta \\
Clúster 3 & $49.3 \%$ & Alta \\
Clúster 1 & $44.6 \%$ & Medio alta \\
Clúster 7 & $14.6 \%$ & Medio \\
Clúster 6 & $-20.1 \%$ & Media baja \\
Clúster 5 & $-24.6 \%$ & Baja \\
Clúster 4 & $-36.8 \%$ & Muy baja \\
\hline
\end{tabular}

Fuente: Elaboración propia a partir del censo de 2002.

Por último, el clúster 2 que representa, al igual que en 1992, a las clases más altas, se reduce en tamaño territorial, pero aumenta en el grado de concentración de ocupaciones vinculadas a grupos dirigentes y profesionales (véase el Cuadro 5). Así, dichas clases viven fuera del límite urbano, en parcelas de media a una hectárea, con baja densidad poblacional, en un suelo con alto valor paisajístico y en la frontera inmediata con tierras indígenas. ${ }^{10}$

\section{Movimientos espaciales de clase en Temuco, 1992-2002}

Cuando se observa a las clases sociales en Temuco durante el periodo intercensal analizado, es posible distinguir áreas inmóviles y

${ }^{9}$ Una hipótesis respecto a lo que ocurrió con estos antiguos trabajadores agrícolas refiere a su absorción por parte de la actividad forestal que rodea a la ciudad.

${ }^{10}$ Temuco está inserta en la región que más concentra población indígena mapuche de Chile. Y producto de la política de entrega de tierras a comunidades indígenas, muchas de las áreas aledañas a las zonas urbanas de la ciudad fueron declaradas no enajenables. 
otras con importantes movimientos espaciales ascendentes y descendentes. Así, y considerando la jerarquía socioespacial de la ciudad, del total de zonas censales analizadas, $12.2 \%$ sube, $7.2 \%$ mantiene, $y$ $80.6 \%$ baja su condición social.

En términos más generales, se constata que gran parte de las zonas urbanas de la ciudad se mantienen o suben en la jerarquía socioespacial, mientras que un número importante de zonas rurales, que representan la mayor parte de las áreas que conforman la comuna de Temuco, tienden a bajar en dicha escala (véase los Mapas 2 y 3 ).

Así, el área rural se pauperiza en términos de jerarquía social, integrando un porcentaje mayor de ocupaciones vinculadas a obreros de baja calificación y trabajadores no calificados. Sin embargo, y a pesar de lo anterior, las zonas rurales también presentan una dualidad social interesante hacia el año 2002. Si bien gran parte de los espacios que integran estas zonas han descendido socialmente, existen algunos enclaves suburbanos de clases altas que aparecieron, los cuales concentran pequeños reductos de dirigentes y profesionales.

\section{Cuadro 6}

Clases socioespaciales presentes en Temuco y porcentaje de ocupados por cada clúster creado, 1992-2002

a) Clases socioespaciales: muy alta y alta

\begin{tabular}{|c|c|c|c|c|}
\hline \multirow[b]{4}{*}{ Ocupaciones } & \multicolumn{4}{|c|}{ Clases socioespaciales } \\
\hline & \multicolumn{2}{|c|}{ Muy alta } & \multicolumn{2}{|c|}{ Alta } \\
\hline & $C 2$ & $C 2$ & C6 & C3 \\
\hline & 1992 & 2002 & 1992 & 2002 \\
\hline Dirigentes & 16.7 & 21.4 & 13.9 & 13.8 \\
\hline Profesionales & 0 & 50 & 24.6 & 33.3 \\
\hline Técnicos & 0 & 21.5 & 7.2 & 16.4 \\
\hline Oficinistas & 29.2 & 0 & 9.4 & 6 \\
\hline Servicios & 29.2 & 0 & 6.8 & 7.6 \\
\hline Agrícolas & 12.5 & 0 & 9.6 & 2.7 \\
\hline Opera. y artesanos & 12.4 & 0 & 3.4 & 1.8 \\
\hline Operadores & 0 & 0 & 7.5 & 2.3 \\
\hline No calificados & 0 & 7.1 & 17.6 & 16.1 \\
\hline Total & 100 & 100 & 100 & 100 \\
\hline
\end{tabular}


b) Clases socioespaciales: media alta, media y media baja

\begin{tabular}{|c|c|c|c|c|c|c|}
\hline \multirow[b]{3}{*}{ Ocupaciones } & \multicolumn{6}{|c|}{ Clases socioespaciales } \\
\hline & \multicolumn{2}{|c|}{ Media alta } & \multicolumn{2}{|c|}{ Media } & \multicolumn{2}{|c|}{ Media baja } \\
\hline & $\begin{array}{c}C 4 \\
1992 \\
\end{array}$ & $\begin{array}{c}C 1 \\
2002\end{array}$ & $\begin{array}{c}C 5 \\
1992 \\
\end{array}$ & $\begin{array}{c}C 7 \\
2002\end{array}$ & $\begin{array}{c}C 1 \\
1992 \\
\end{array}$ & $\begin{array}{c}C 6 \\
2002 \\
\end{array}$ \\
\hline Dirigentes & 9.1 & 8.3 & 5.9 & 6.9 & 3.8 & 4.7 \\
\hline Profesionales & 19.9 & 25.2 & 10.2 & 13.6 & 2.2 & 5.3 \\
\hline Técnicos & 10 & 21.2 & 7.3 & 16.7 & 0.6 & 11.1 \\
\hline Oficinistas & 15.9 & 10.4 & 13.5 & 10.9 & 0.6 & 9.3 \\
\hline Servicios & 14.7 & 13.2 & 19.1 & 17.3 & 5.8 & 17.6 \\
\hline Agrícolas & 1.4 & 1.2 & 2 & 1.1 & 62.7 & 1.5 \\
\hline Opera. y artesanos & 8.5 & 5.5 & 17.1 & 11.5 & 6 & 18.6 \\
\hline Operadores & 5.2 & 4.9 & 7.5 & 8.3 & 2 & 9.4 \\
\hline No calificados & 15.3 & 10.1 & 17.4 & 13.7 & 16.3 & 22.5 \\
\hline Total & 100 & 100 & 100 & 100 & 100 & 100 \\
\hline
\end{tabular}

c) Clases socioespaciales: baja y muy baja

Clases socioespaciales

\begin{tabular}{lccccc}
\cline { 2 - 3 } & \multicolumn{3}{c}{ Baja } & & \multicolumn{2}{c}{ Muy baja } \\
\cline { 2 - 3 } \cline { 5 - 6 } Ocupaciones & $\boldsymbol{C 7}$ & $\mathbf{C 5}$ & & $\boldsymbol{C 3}$ & $\boldsymbol{C 4}$ \\
\hline Dirigentes & 2.4 & 4.4 & & 2.4 & 2.6 \\
Profesionales & 3.7 & 4.5 & & 1.6 & 4.2 \\
Técnicos & 4.5 & 10.5 & & 3.1 & 3.8 \\
Oficinistas & 8.9 & 8.3 & & 3.6 & 0.7 \\
Servicios & 18.5 & 17.4 & & 12.1 & 5.6 \\
Agrícolas & 2.9 & 2.6 & & 17.3 & 35 \\
Opera. y artesanos & 27.1 & 18.4 & & 26.4 & 12.5 \\
Operadores & 9.6 & 7.6 & & 7 & 2 \\
No calificados & 22.4 & 26.3 & & 26.5 & 33.6 \\
Total & 100 & 100 & & 100 & 100 \\
\hline
\end{tabular}

Fuente: Elaboración propia a partir de censos de 1992 y 2002. 


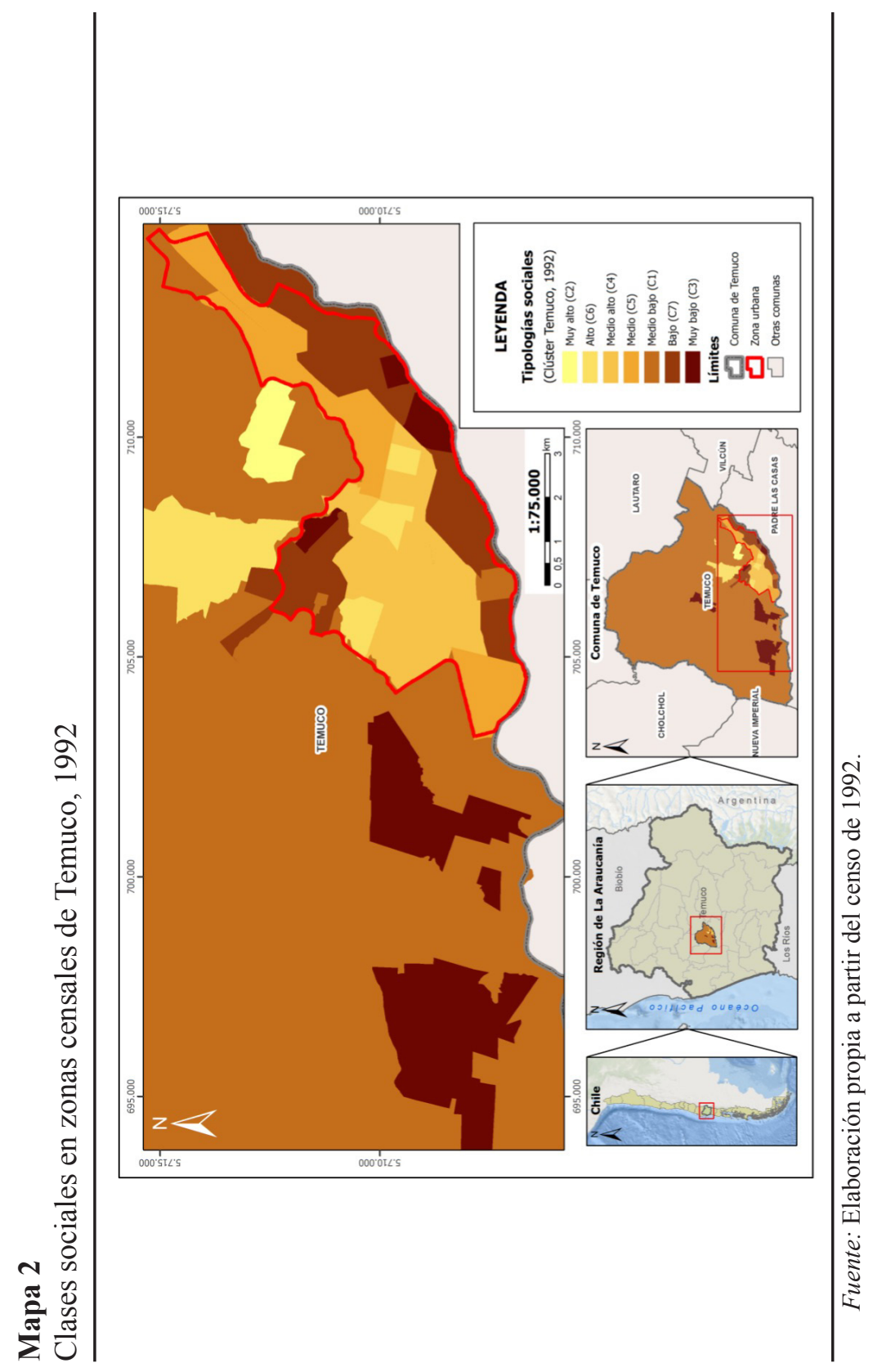




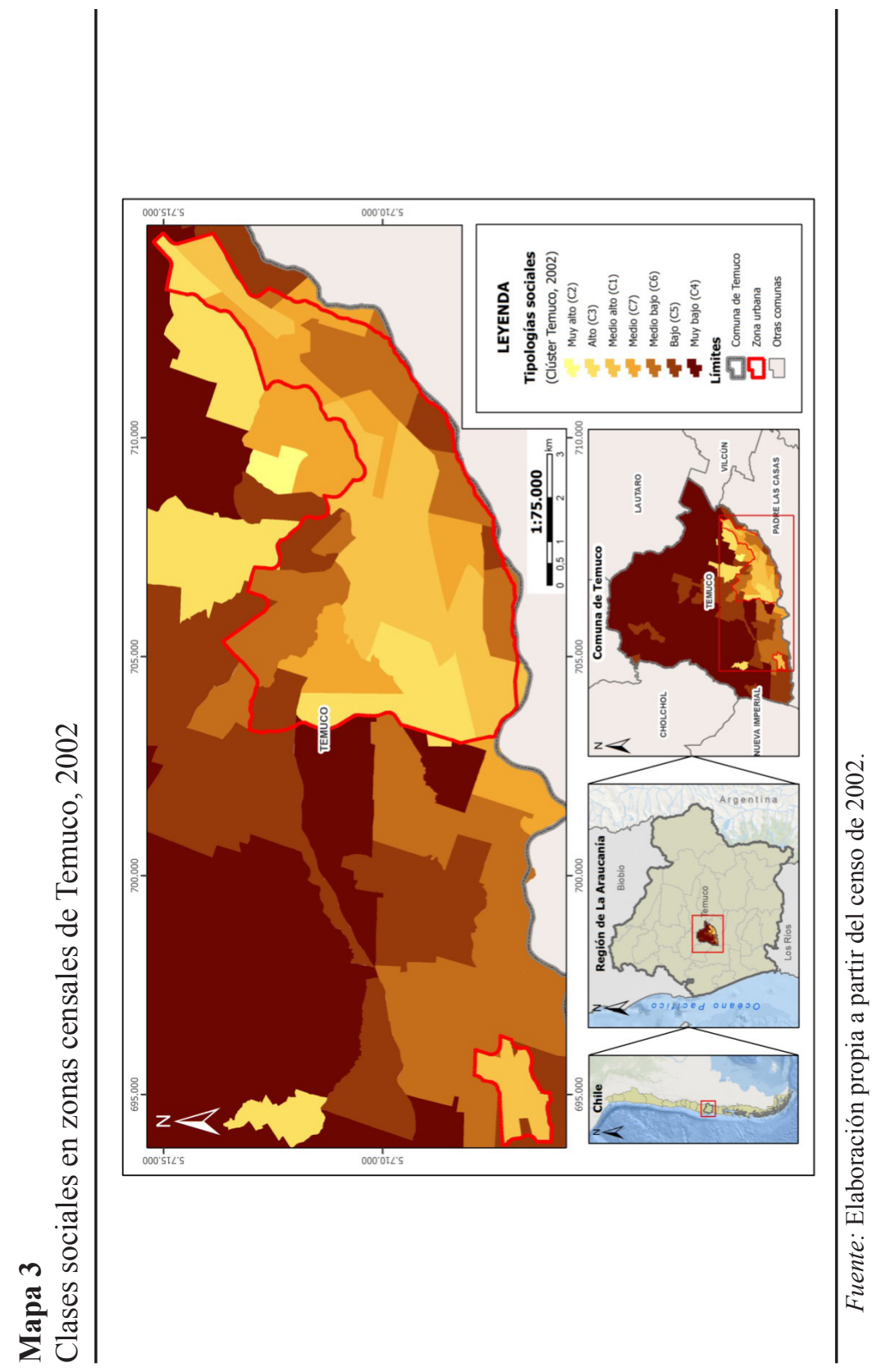


Una de estas zonas corresponde al área que conecta Temuco y Labranza, ${ }^{11}$ espacio urbano de gran atractivo para las clases medias del último tiempo. En este sentido, dichas zonas censales ascendieron entre uno y dos puestos en la jerarquía socioespacial en el periodo 1992-2002, pasando muchos de ellos de ser áreas integradas por clases medias bajas a espacios que concentran a clases altas (véase el Cuadro 7).

Esta localización suburbana de las clases más altas de Temuco parece estar enmarcada dentro del movimiento espacial histórico de este grupo. Con la fundación de la ciudad, la elite comercial local, formada principalmente por migrantes alemanes y franceses, vivía en áreas poco urbanizadas al poniente de Temuco, en lo que hoy se conoce como Avenida Alemania (Toledo, Romero y Garín, 2000). Así, en la medida que la ciudad se fue extendiendo en esta dirección, dichos sectores fueron buscando nuevos espacios suburbanos, alejados de áreas urbanas consolidadas.

En cuanto a los cambios sociales experimentados en las zonas urbanas de Temuco, es posible observar que una parte importante del área central tiende a mantener su condición social. Con excepción de algunas zonas, como el centro histórico y parte de Avenida Alemania, las cuales bajan de categoría social de alta a media alta, en el resto de las áreas no se observan cambios, lo cual da cuenta de la poca valoración social por habitar el centro de la ciudad en aquel entonces. Aun así, esta zona central de la ciudad conserva a las clases medias, las cuales se extienden espacialmente de este a oeste, siguiendo la morfología del área urbana de Temuco (véase el Mapa 4).

Siguiendo lo anterior, los pocos reductos espaciales que concentran a clases más altas en esta gran zona media durante 1992 (uno de los cuales corresponde al centro histórico de la ciudad), se desplazan a un área del sector poniente en el año 2002, el cual hoy es conocida como barrio inglés. Esta zona, además, representa el área que más

${ }^{11}$ Labranza es un área urbana desacoplada de la ciudad consolidada producto de la política de vivienda social en la década del noventa. En este sentido, dicha política tuvo que enfrentar la escasez de suelo urbano en el área céntrica resultado de la mercantilización del espacio. A esto se suman las restricciones de expansión suburbana debido a un entorno de propiedades indígenas. 


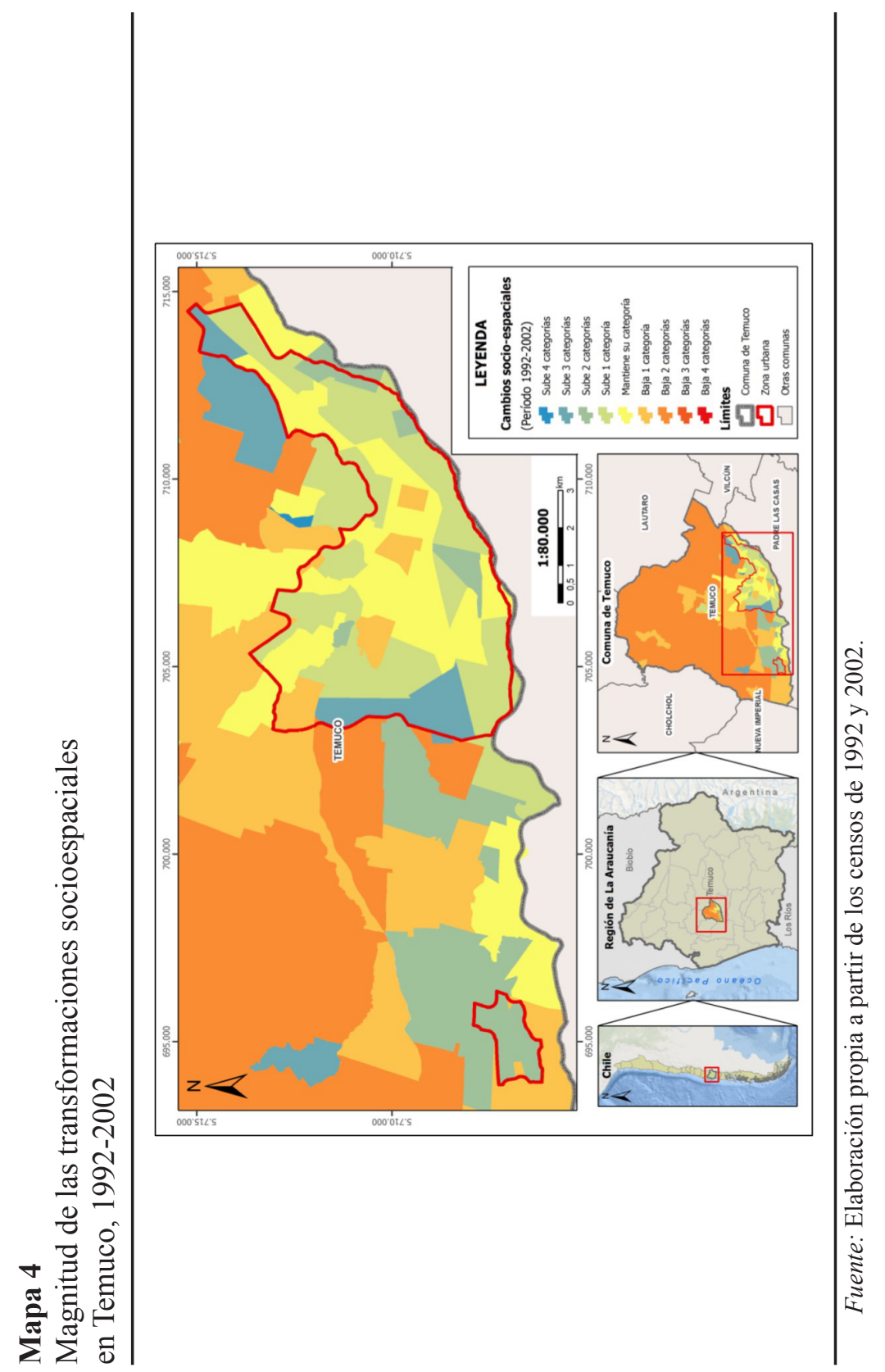


sube en términos de jerarquía socioespacial entre los años analizados, pasando de concentrar clases medias bajas a clases altas (véase el Mapa 2 y el Cuadro 7).

\section{Cuadro 7}

Áreas relevantes de Temuco y sus transformaciones espaciales de clases sociales, 1992-2002

\begin{tabular}{|c|c|c|c|c|c|}
\hline $\begin{array}{l}\text { Áreas } \\
\text { relevantes }\end{array}$ & $\begin{array}{c}\text { Sectores } \\
\text { específicos }\end{array}$ & $\begin{array}{c}\text { Clases } \\
\text { sociales } \\
1992 \\
\end{array}$ & $\begin{array}{c}\text { Dirección e } \\
\text { intensidad } \\
\text { cambio de clase } \\
1992-2002\end{array}$ & $\begin{array}{c}\text { Clases } \\
\text { sociales } 2002\end{array}$ & $\begin{array}{c}\text { Nivel } \\
\text { transformación } \\
\text { socioespacial } \\
1992-2002 \\
\end{array}$ \\
\hline \multirow[t]{2}{*}{ Rurales } & $\begin{array}{l}\text { Entidades } \\
\text { rurales } \\
\text { alejadas } \\
\text { ciudad }\end{array}$ & Media baja & 2 escaños & Muy baja & $\begin{array}{c}\text { Gran } \\
\text { transformación }\end{array}$ \\
\hline & $\begin{array}{c}\text { Entre } \\
\text { Temuco } \\
\text { y Labranza }\end{array}$ & Muy baja & $\begin{array}{c}\text { 亿 } \\
2 \text { escaños }\end{array}$ & Media baja & $\begin{array}{c}\text { Gran } \\
\text { transformación }\end{array}$ \\
\hline \multirow[t]{4}{*}{ Suburbanas } & $\begin{array}{l}\text { Camino } \\
\text { a Cholchol }\end{array}$ & Media baja & 1 escaño & Baja & $\begin{array}{c}\text { Transformación } \\
\text { parcial }\end{array}$ \\
\hline & $\begin{array}{l}\text { Salida norte } \\
\text { (nororiente) }\end{array}$ & Media baja & 2 escaños & Muy baja & $\begin{array}{c}\text { Gran } \\
\text { transformación }\end{array}$ \\
\hline & Lanín & Muy baja & $\begin{array}{c}\text { 〔 } \\
1 \text { escaño }\end{array}$ & Baja & $\begin{array}{c}\text { Transformación } \\
\text { parcial }\end{array}$ \\
\hline & $\begin{array}{c}\text { Ribera } \\
\text { del Cautín }\end{array}$ & Muy baja & 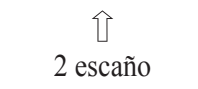 & Media baja & $\begin{array}{c}\text { Gran } \\
\text { transformación }\end{array}$ \\
\hline \multirow[t]{3}{*}{ Urbanas } & Centro & Alta & 1 escaños & Media alta & $\begin{array}{c}\text { Transformación } \\
\text { parcial }\end{array}$ \\
\hline & $\begin{array}{l}\text { Barrio } \\
\text { Inglés }\end{array}$ & Media baja & $\begin{array}{c}\text { 介 } \\
2 \text { escaños }\end{array}$ & Alta & $\begin{array}{c}\text { Gran } \\
\text { transformación }\end{array}$ \\
\hline & Labranza & Media baja & $\begin{array}{c}\text { 厄 } \\
1 \text { escaño }\end{array}$ & Media & $\begin{array}{c}\text { Transformación } \\
\text { parcial }\end{array}$ \\
\hline
\end{tabular}

Fuente: Elaboración propia.

De esta manera, mientras que en el centro de la ciudad se observa un leve proceso de tugurización, donde aumentan principalmente los grupos obreros y disminuye la presencia de dirigentes, profesionales y técnicos de alta calificación, en la zona poniente de la ciudad 
es posible constatar acciones gentrificadoras, las cuales involucraron la extensión de la ciudad hacia terrenos agrícolas y/o indígenas. ${ }^{12}$

Otras de las áreas que experimenta un gran ascenso en la escala social dentro de la zona urbana de la ciudad corresponden, por un lado, a aquellos sectores localizados en la franja sur de Temuco, siguiendo la ribera del río Cautín, como Amanecer, Santa Elena y Santa Rosa, y, por otro lado, al norte, en espacios pertenecientes al sector denominado Lanín. Todas estas zonas representaban áreas de la ciudad que concentraban clases bajas, las cuales suben entre una y dos categorías sociales entre 1992 y 2002 (véase el Cuadro 7).

Es necesario agregar que la extensa zona localizada en la ribera del río Cautín representó, desde la fundación de la ciudad a fines del siglo XIX, el espacio de recepción de una parte importante de los migrantes rurales del entorno de Temuco; tales movimientos migratorios se intensificaron a raíz de la crisis agrícola que sufrió la región en la primera mitad del siglo XX (Pinto, 2007). En este sentido, la concentración de clases bajas, representadas por grupos obreros y no calificados, es una condición que obedece a la producción sociohistórica de dicho espacio, la cual fue dando paso a un área más mixturada socialmente hacia el año 2002.

\section{Conclusiones}

La ciudad de Temuco experimentó importantes transformaciones socioespaciales entre 1992 y 2002. Entre ellas destaca un periurbano cada vez más ecléctico por el aumento de clases bajas y la persistencia, en pequeños enclaves, de las clases más altas de la ciudad. Todo lo anterior, además, en territorios indígenas, lo cual implica la existencia de posibles tensiones sobre esta área fuertemente demandada en los últimos años.

${ }^{12}$ Actualmente las tierras indígenas que están en la frontera inmediata de la ciudad son altamente demandadas, lo cual trae como consecuencia la implementación de estrategias del mercado inmobiliario para usarlas. Una de ellas es el lobby en el parlamento chileno, con el fin de que la ley de propiedad indígena del suelo sea modificada. 
En la actualidad, este periurbano ha concentrado a clases medias altas que buscan la amenidad natural que ofrecen estas zonas. El mercado inmobiliario ya muestra signos de comprender este gusto espacial, razón por la cual ha aumentado la presencia de proyectos de primera y segunda residencia, tal como ocurre en áreas suburbanas de otras ciudades en Chile (Hidalgo, Borsdorf y Plaza, 2009; Hidalgo, Arenas y Santana, 2016).

En los espacios urbanos, la aparición de profesionales y técnicos de nivel medio en zonas históricamente obreras y de clases bajas genera un espacio más mixturado socialmente. En especial, en aquellos territorios del sur de la ciudad que albergaron a migrantes rurales en el pasado. Sin embargo, es difícil estimar con los datos trabajados si este aumento se debe a la llegada de grupos medios a este espacio o, por el contrario, corresponde a un proceso de ascenso horizontal en la estatificación social, donde los hijos superan a sus padres en términos educacionales. En cualquiera de los dos casos, el desafío futuro es entender el tipo de gusto espacial de clase que está detrás de estas formas de habitar, para lo cual es necesario un trabajo con enfoque de métodos mixtos.

Aun así, las posibilidades de mixtura socioespacial existentes en estas zonas muestran que dicha experiencia puede darse sin la participación explícita de políticas estatales en esta materia. Esto abre un importante debate en torno a las posibilidades de integración socioespacial en Chile, vinculando a esta reflexión no sólo los aspectos relacionados con las disposiciones positivas que tienen distintas clases respecto a dicha integración debido a la falta de impedimentos culturales y sociológicos (Sabatini y Brain, 2008; Sabatini et al., 2012; Wormald et al., 2012), o la discusión un tanto recursiva sobre integración social (Sabatini, Cáceres y Cerda, 2001; Sabatini y Vergara, 2018) y cohesión social (Rasse, 2015), sino también aquellas dimensiones relacionadas con los patrones de movilidad en la estructura social de los territorios.

En cuanto a las clases medias, éstas se diversifican por el espacio en el periodo analizado, bajando de esta forma el grado de concentración en el centro de la ciudad. Esto obedece, entre otros factores, a la diversificación de la clase media en el contexto nacional (Méndez, 2008; Gayo, Méndez y Teitelboim, 2016), hecho que hace que 
su presencia se extienda en distintas zonas urbanas. En este escenario, especialmente es relevante la aparición de clases medias altas hacia el poniente de la ciudad, área integrada en su gran mayoría por profesionales inmigrantes de otras zonas de la región o el país, y que en la actualidad representa un área consolidada en este perfil socioespacial.

Las conclusiones anteriores introducen importantes diferencias respecto al estudio de segmentación socioespacial efectuado por Garín, Salvo y Bravo (2009) en la ciudad de Temuco. Sus resultados indican que entre los años 1992 y 2002 los niveles de segregación residencial, medidos a partir del índice de disimilitud de Duncan en una escala correspondiente a los distritos censales, se mantienen e incluso aumentan en ciertos sectores de la ciudad. Especialmente 1lama la atención que, bajo esta metodología, la franja espacial obrera que recorre del nororiente al surponiente de la ciudad se mantenga sin cambios, cuando en el presente estudio precisamente esa zona es una de las que experimenta la mayor transformación en términos de mixtura social en el periodo analizado.

A partir de estos resultados diferenciados respecto al grado de convivencias de clases en la ciudad, dos son los antecedentes que se deben evaluar: por un lado, el proxy a la clase social en el trabajo de Garín, Salvo y Bravo (2009) se vincula a la educación del jefe de hogar, lo cual deja fuera la categoría ocupacional, una de las principales variables en la construcción de la clase social desde un punto de vista marxista y weberiano. Por otro lado, las escalas de aplicación de los niveles de segmentación social son diferentes. En este último punto, dicho estudio no se hace cargo del problema de las áreas de concentración o "problema de la grilla" (Ruiz-Tagle y López-Morales, 2014), frente al cual se recomienda incluir unidades espaciales pequeñas, para posteriormente ir asociando las contigüidades correspondientes.

A partir de lo anterior, el tratamiento de fuentes censales puede dar resultados diferenciados dependiendo de las variables y el tipo de análisis que se aplique. El presente trabajo buscó, en este sentido, no sólo mostrar las transformaciones espaciales de clases sociales en la ciudad de Temuco, sino también un tipo de metodología distinta que permita abrir el debate respeto a cómo observar los espacios urbanos y sus cambios en la actualidad. 


\section{Bibliografía}

Barozet, E., Espinoza, V., Holz, R. y Sepúlveda, D. (2009). Estratificación social en regiones: ¿qué oportunidades ofrecen las regiones en Chile? Informe preparado para la Subsecretaría de Desarrollo Regional, Chile.

Bourdieu, P. (1989). Social space and symbolic power. Sociological Theory, 7(1), 14-25. www.jstor.org/stable/202060

Bourdieu, P. (1997). Razones prácticas. Barcelona: Anagrama.

Bourdieu, P. (2006). La distinción. Criterios y bases sociales del gusto. Madrid: Taurus.

Bourdieu, P. (2018). Social space and the genesis of appropriated physical space. International Journal of Urban and Regional Research, 42(1), 106-114. https://onlinelibrary.wiley.com/doi/ full/10.1111/1468-2427.12534

Brenner, N. (2013). Tesis sobre la urbanización planetaria. Revista Nueva Sociedad, 243, 38-66. https://static.nuso.org/media/articles /downloads/3915_1.pdf

Bridge, G. (2001). Bourdieu, rational action and the time-space strategy of gentrification. Transactions of the Institute of British Geographers, 26(2), 205-216. www.jstor.org/stable/3650668 Ciccolella, P. (1999). Globalización y dualización en la región metropolitana de Buenos Aires. Grandes inversiones y reestructuración socioterritorial en los años noventa. Revista Latinoamericana de Estudios Urbano Regionales, Eure, 25(76), 5-27. https://scielo.conicyt.cl/scielo.php?script=sci_arttext\&pid $=\mathrm{S} 0250-71611999007600001$

De Mattos, C. (2002). Mercado metropolitano de trabajo y desigualdades sociales en el Gran Santiago. ¿Una ciudad dual? Revista Latinoamericana de Estudios Urbano Regionales, Eure, 28(85), 51-70. http://www.eure.cl/index.php/eure/article/view/1241

Engels, F. (2006). Contribución al problema de la vivienda. Madrid:

Fundación de Estudios Socialistas Federico Engels.

Erikson, R. y Goldthorpe, J. (1992). The constant flux: A study of class mobility in industrial societies. Oxford: Clarendon Press.

Espinoza, V., Barozet, E. y Méndez, M. L. (2013). Estratificación y movilidad social bajo un modelo neoliberal maduro: el caso de 
Chile. Revista Lavboratorio, 25, 169-192. https://publicaciones. sociales.uba.ar/index.php/lavboratorio/article/view/125/112

Friedman, S., Savage, M. y Miles, A. (2015). Cultural sociology and new forms of distinction. Poetics, 53, 1-8. https://www.science direct.com/science/article/pii/S0304422X15000753

Fuentes, L. y Link, F. (2014). Competitividad, mercados del trabajo y estructura socioterritorial en Bogotá, Lima y Santiago. Revista Geografia Norte Grande, 59, 105-122. https://scielo.conicyt.cl/ pdf/rgeong/n59/art07.pdf

Fuentes, L., Mac-Clure, O., Moya, C. y Olivos, C. (2017). Santiago de Chile: ¿ciudad de ciudades? Desigualdades sociales en zonas de mercado laboral local. Revista CEPAL, 121, 93-109. https://www. cepal.org/es/publicaciones/41146-santiago-chile-ciudad-ciudades -desigualdades-sociales-zonas-mercado-laboral

Garín, A., Salvo, S. y Bravo, G. (2009). Segregación residencial y políticas de vivienda en Temuco. 1992-2002. Revista de Geografia Norte Grande, 44, 113-128. https://scielo.conicyt.cl/scielo. php?script=sci_arttext\&pid=S0718-34022009000300006

Gayo, M., Méndez, M. L. y Teitelboim, B. (2016). La terciarización en Chile. Desigualdad cultural y estructura ocupacional. Revista CEPAL, 119, 187-207. https://www.cepal.org/sites/default/files/ publication/files/40400/RVE119_Gayo.pdf

Hamnett, C. y Butler, T. (2013). Re-classifying London: A growing middle class and increasing inequality. Journal City, 17(2), 197208. https://www.tandfonline.com/doi/full/10.1080/13604813.2 013.765719

Hanquinet, L., Savage, M. y Callier, L. (2013). Elaborating Bourdieu's field analysis in urban studies: Cultural dynamics in Brussels. Journal Urban Geography, 33(4), 508-529. https://www. tandfonline.com/doi/abs/10.2747/0272-3638.33.4.508

Harvey, D. (2014). Ciudades rebeldes. Del derecho de la ciudad a la revolución urbana. Buenos Aires: Akal.

Hidalgo, R., Arenas, F. y Santana, D. (2016). ¿Utópolis o distópolis?: producción inmobiliaria y metropolización en el litoral central de Chile (1992-2012). Revista Latinoamericana de Estudios Urbano Regionales, Eure, 42(126), 27-54. https://scielo.conicyt.cl/ $\mathrm{pdf} /$ eure/v42n126/art02.pdf 
Hidalgo, R., Borsdorf, A. y Plaza, F. (2009). Parcelas de agrado alrededor de Santiago y Valparaíso. ¿Migración por amenidad a la chilena? Revista de Geografia Norte Grande, 44, 93-112. https:// scielo.conicyt.cl/pdf/rgeong/n44/art05.pdf

Horbath, J. (2002) El trabajo y la Ciudad de México: una revisión desde la geografia de las actividades productivas urbanas. Scripta Nova, 7(119). http://revistes.ub.edu/index.php/ScriptaNova/ article/view/523

INE. (2018). Censo de Población y Vivienda 2017. Instituto Nacional Electoral. http://www.censo2017.cl/microdatos/

Lebart, L., Morineau, A. y Piron, M. (1995). Statisitique exploratoire multidimensionnelle. París: Dunod.

Lefebvre, H. (2013). La producción del espacio. Madrid: Capitán Swing.

León, A. y Martínez, J. (2001). La estratificación social chilena hacia fines del siglo XX. Revista CEPAL, 52, 1-39. https://ideas.repec. org/p/ecr/col041/6009.html

Ley, D. (1980). Liberal ideology and post-industrial city. Annals of the Association of American Geographers, 70(2), 238-258. https: //www.jstor.org/stable/2562952

Link, F., Valenzuela, F. y Fuentes, L. (2015). Segregación, estructura y composición social del territorio metropolitano en Santiago de Chile. Complejidades metodológicas en el análisis de la diferenciación social en el espacio. Revista de Geografia Norte Grande, 62, 151-168. https://scielo.conicyt.cl/scielo.php?script=sci_ arttext\&pid=S0718-34022015000300009

Mac-Clure, O. (2012). Las nuevas clases medias en Chile: un análisis de cohortes. Revista CEPAL, 108, 169-182. https://www. un-ilibrary.org/content/journals/16820908/2012/108/9

Mac-Clure, O., Barozet, E. y Maturana, V. (2014). Desigualdad, clase media y territorio en Chile: ¿clase media global o múltiples mesocracias según territorios? Revista Latinoamericana de Estudios Urbano Regionales, Eure, 40(121), 163-183. https://scielo.conicyt.cl/scielo.php?script=sci_arttext\&pid=S0 250-71612014000300008

Marchant, C., Frick, J. y Vergara, L. (2016). Urban growth trends in midsize Chilean cities: The case of Temuco. Urbe. Revista Bra- 
sileira de Gestão Urbana, 8(3), 375-389. http://www.scielo.br/ pdf/urbe/v8n3/2175-3369-urbe-2175-3369008003A007.pdf Martínez, J. y Tironi, E. (1985). Las clases sociales en Chile: cambio y estratificación, 1970-1980. Santiago: Ediciones Sur.

Méndez, M. L. (2008). Middle class identities in a neoliberal age: Tensions between contested authenticities. The Sociological Review, 56(2), 220-237. https://journals.sagepub.com/doi/full /10.1111/j.1467-954X.2008.00785.x

Pinto, J. (2007). Expansión económica y conflicto mapuche. La Araucanía, 1900-1940. Revista de Historia Social y de las Mentalidades, 1(11), 9-34. http://www.revistas.usach.cl/ojs/index.php /historiasocial/article/view/208/195

Portes, A. y Hoffman, K. (2003). Latin American class structures: Their composition and change during the neoliberal era. Latin American Research Review, 38(1), 41-82. https://www.jstor.org/ stable/1555434

Preteceille, E. y Ribeiro, L. (1999). Tendências da segregaçao social em metrópoles globais e desiguais: Paris e Rio de Janeiro nos anos 80. Revista Latinoamericana de Estudios Urbano Regionales, Eure, 26(76), 79-102. https://scielo.conicyt.cl/scielo. php? script $=$ sci_arttext\&pid $=$ S0250-71611999007600004\& lng=en\&nrm=iso\&tlng=en

Raczynski, D. (1973). Tasas y pautas de movilidad ocupacional en el Gran Santiago. Cuadernos de Economía, 10(29), 66-95. https:// econpapers.repec.org/article/ioecuadec/v_3a10_3ay_3a1973_3a i_3a29_3ap_3a66-95.htm

Rasse, A. (2015). Juntos, pero no revueltos. Procesos de integración social en fronteras residenciales entre hogares de distinto nivel socioeconómico. Revista Latinoamericana de Estudios Urbano Regionales, Eure, 41(122), 125-143. https://scielo.conicyt.cl/ $\mathrm{pdf} /$ eure/v41n122/art06.pdf

Ripoll, F. y Tissot, S. (2010). La dimension spatiale des ressources sociales. Regards Sociologiques, 40, 5-7. https://halshs.archives -ouvertes.fr/halshs-01665981

Rodríguez, J. (2001). Segregación residencial socioeconómica: ¿qué es?, ¿cómo se mide?, ¿qué está pasando?, ¿importa? Revista CEPAL, 16, 1-79. https://www.cepal.org/es/publicaciones 
/7149-segregacion-residencial-socioeconomica-que-es-como -se-mide-que-esta-pasando

Ruíz-Tagle, J. y López-Morales, E. (2014). El estudio de la segregación residencial en Santiago de Chile: revisión crítica de algunos problemas metodológicos y conceptuales. Revista Latinoamericana de Estudios Urbano Regionales, Eure, 40(119), 25-48. https://scielo.conicyt.cl/scielo.php?script=sci_arttext\&pid= S0250-71612014000100002

Sabatini, F. y Brain, I. (2008). La segregación, los guetos y la integración social urbana: mitos y claves. Revista Latinoamericana de Estudios Urbano Regionales, Eure, 34(103), 5-26. https:// scielo.conicyt.cl/pdf/eure/v34n103/art01.pdf

Sabatini, F., Cáceres, G. y Cerda, J. (2001). Segregación residencial en las principales ciudades chilenas: tendencias de las tres últimas décadas y posibles cursos de acción. Revista Latinoamericana de Estudios Urbano Regionales, Eure, 27(82), 21-42. http://www.eure.cl/index.php/eure/article/view/1258

Sabatini, F., Rasse, A., Mora, P. y Brain, I. (2012). ¿Es posible la integración residencial en las ciudades chilenas? Disposición de los grupos medios y altos a la integración con grupos de extracción popular. Revista Latinoamericana de Estudios Urbano Regionales, Eure, 38(115), 17-34. https://scielo.conicyt.cl/pdf/ eure/v38n115/art08.pdf

Sabatini, F. y Vergara, L. (2018). ¿Apoyo a lugares o apoyo a personas? Dos proyectos chilenos de vivienda socialmente integrada. Revista INVI, 33(94), 9-48. https://scielo.conicyt.cl/pdf/invi/ v33n94/0718-8358-invi-33-94-00009.pdf

Savage, M., Devine, F., Cunningham, N., Taylor, M., Li, Y., Hjellbrekke, J., Le Roux, B., Friedman, S. y Miles, A. (2013). A new model of social class? Findings from the BBC's Great British class survey experiment. Sociology, 47(2), 219-250. https://journals. sagepub.com/doi/pdf/10.1177/0038038513481128

Savage, M., Dickens, P. y Fielding, T. (1988). Some social and political implications of the contemporary fragmentation of the service class in Britain. International Journal of Urban and Regional Research, 12(3), 455-476. https://onlinelibrary.wiley.com/doi/ abs/10.1111/j.1468-2427.1988.tb00089.x 
Simmel, G. (1986). Sociología 1. Estudios sobre las formas de socialización. Madrid: Alianza.

Smith, N. (2012). La nueva frontera urbana. Ciudad revanchista y gentrificación. Madrid: Traficantes de Sueños.

Toledo, X., Romero, H. y Garín, A. (2000). Segregación socioespacial en Temuco. Espacio y Desarrollo, 12, 104-22. http://revistas. pucp.edu.pe/index.php/espacioydesarrollo/article/view/8091

Torche, F. y Wormald, G. (2004). Estratificación y movilidad social en Chile: entre la adscripción y el logro. Revista CEPAL, 98, 1-85. https:/www.cepal.org/es/publicaciones/6089-estratificacionmovilidad-social-chile-la-adscripcion-logro

Vergara, L., Gola, R. y Huiliñir, V. (2015). Los inicios de la insustentabilidad: problemas urbanos e institucionalidad en la ciudad de Temuco, 1955-1970. Cuadernos de Vivienda y Urbanismo, 8(16), 264-281. https://revistas.javeriana.edu.co/index.php/cvyu /article/view/14683

Weber, M. (2014). Economía y sociedad. México: Fondo de Cultura Económica.

Wormald, G., Flores, C., Sabatini, F., Trebilcock, M. y Rasse, A. (2012). Cultura de cohesión e integración en las ciudades chilenas. Revista INVI, 27(76), 117-145. https://scielo.conicyt.cl/pdf/ invi/v27n76/art04.pdf

\section{Acerca de los autores}

Félix Rojo Mendoza es doctor en Geografía por el Instituto de Geografía de la Pontificia Universidad Católica de Chile; tiene una maestría en Investigación Social y Desarrollo, y es sociólogo por la Universidad de Concepción. Actualmente se desempeña como profesor adjunto del Departamento de Sociología y Ciencia Política de la Universidad Católica de Temuco, donde fue director de Sociología entre los años 2013 y 2014. Es director del Observatorio de Dinámicas del Sur (Odisur) de la misma universidad. Sus líneas de investigación son la sociología y geografía urbanas, particularmente las transformaciones socioespaciales en las ciudades actuales. ORCID: https://orcid.org/0000-0001-5794-5652 
Entre sus publicaciones destacan:

Rojo, F. y Mercado, C. (2019). La estratificación socioespacial en contexto indígena: el caso de Temuco, 1992-2002. Revista Electrónica de Geografía y Ciencias Sociales, Scripta Nova, 23(623). 1-28. https://revistes.ub.edu/index.php/ScriptaNova/article/view $/ 22170 / 30053$

Rojo, F. y Hernández, J. (2019). Colonización y nuevo territorio: la formación de la elite comercial de Temuco, 1885-1913. Revista de Geografia Norte Grande, 73, 185-209. https://scielo.conicyt. $\mathrm{cl} / \mathrm{pdf} /$ rgeong/n73/0718-3402-rgeong-73-00185.pdf

Rojo, F., Jara, T. y Frick, J. (2019). Las urbanizaciones cerradas en la ciudad intermedia: el caso de Temuco (Chile), 2005-2014. Revista Bitácora Urbano-Territorial, 29(1), 79-90. https://revistas. unal.edu.co/index.php/bitacora/article/view/63192/pdf

Rodrigo Hidalgo Dattwyler es doctor en Geografía Humana por la Universidad de Barcelona, y geógrafo por la Pontificia Universidad Católica de Chile (UC). Es profesor titular y director del Doctorado en Geografía en el Instituto de Geografía de la UC. Sus líneas de investigación son la geografía urbana, en especial las transformaciones socioespaciales producto de la acción del capital. ORCID: https:// orcid.org/0000-0001-6092-1547

Entre sus publicaciones se encuentran:

Hidalgo, R., Santana, D. y Link, F. (2018). New neoliberal public housing policies: Between centrality discourse and peripheralization practices in Santiago, Chile. Journal Housing Studies, 34(3), 489-518. https://www.tandfonline.com/doi/full/10.1080/0 2673037.2018.1458287

Hidalgo, R., Alvarado, V., Santana, D. y Paulsen, A. (2018). Metaespacio: la cáscara cosmopolita de un entorno inventado. Representaciones sobre el Barrio Italia, Santiago de Chile. Estudios Demográficos y Urbanos, 33(1), 79-110. https://estudios demograficosyurbanos.colmex.mx/index.php/edu/article/ view/1728/pdf

Jiménez, V., Hidalgo, R., Campesino, A. J. y Alvarado, V. (2018). Normalización del modelo neoliberal de expansión residencial más allá del límite urbano en Chile y España. Revista La- 
tinoamericana de Estudios Urbano Regionales, Eure, 44(132), 27-46.https://scielo.conicyt.cl/pdf/eure/v44n132/0250-7161-eure44-132-0027.pdf

Recepción: 11 de diciembre de 2018. Aceptación: 6 de noviembre de 2019. 
